\title{
Serum levels of matrix metalloproteinase-9 predict lymph node metastasis in breast cancer patients
}

\author{
DONG SIK HEO ${ }^{1}$, HOON CHOI $^{1}$, MI YOUNG YEOM ${ }^{2}$, BYUNG JOO SONG ${ }^{3}$ and SE JEONG OH ${ }^{1}$ \\ Departments of ${ }^{1}$ Surgery and ${ }^{2}$ Clinical Research Laboratory, Incheon St. Mary's Hospital, College of Medicine, \\ The Catholic University of Korea, Incheon; ${ }^{3}$ Department of Surgery, Seoul St. Mary's Hospital, \\ College of Medicine, The Catholic University of Korea, Seoul, Republic of Korea
}

Received December 18, 2013; Accepted January 13, 2014

DOI: $10.3892 /$ or.2014.3001

\begin{abstract}
Matrix metalloproteinases (MMPs) are proteolytic enzymes that play important roles in cancer progression and metastasis. Although serum MMP expression is known to correlate with the primary lesion of breast cancer, there has yet to be a study regarding the correlation between serum MMP expression and metastatic lesions, particularly lymph nodes. The present study evaluated the correlation of serum and lymph node MMP expression with axillary node metastasis. The preoperative serum levels of MMP-2 and MMP-9 in 77 patients with breast cancer and in 10 patients with benign breast tumor were determined by ELISA and zymography. One hundred and twelve axillary lymph nodes were collected for zymography during breast cancer surgery. Significantly higher serum levels of MMP-2 and MMP-9 were found in breast cancer patients compared to patients with benign tumor. High serum levels of MMP-2 and MMP-9 were significantly associated with node metastasis. ELISA and zymography results for serum MMP-2 and MMP-9 correlated significantly, with a Pearson correlation coefficient ( $\mathrm{r}$ ) of 0.76 for MMP-2 $(\mathrm{P}=0.001)$ and 0.81 for MMP-9 $(\mathrm{P}=0.001)$. In terms of lymph node, total MMP-2, MMP-9 and MMP-9 activity were significantly higher in metastatic than in non-metastatic nodes. There was a correlation between serum and lymph node MMP-9 levels on zymographic measurements $(\mathrm{r}=0.34, \mathrm{P}=0.011)$, but not in terms of MMP-2 levels. Serum MMP-9 levels may have a diagnostic value for predicting axillary node metastasis.
\end{abstract}

\section{Introduction}

Primary breast cancer patients can be treated with adjuvant systemic chemotherapy after surgical removal according

Correspondence to: Professor Se Jeong Oh, Department of Surgery, Incheon St. Mary's Hospital, College of Medicine, The Catholic University of Korea, 56 Dongsu-Ro, Bupyung-Gu, Incheon 403-720, Republic of Korea

E-mail: ohsj@catholic.ac.kr

Key words: biological marker, matrix metalloproteinase-2, matrix metalloproteinase-9, breast cancer to classic predictive and prognostic factors, such as lymph node status, nuclear grade, histologic grade, tumor size, estrogen/progesterone receptor status and C-erb-B2 expression (1). Among these factors, axillary lymph node status is recognized as the best clinical parameter. Based on these biomarkers, adjuvant systemic therapy is recommended to patients. However, currently available biomarkers are relatively inaccurate in predicting prognosis (2). Therefore, many patients may have overtreatment or insufficient treatment. Thus, additional biomarkers need to be established to ensure a more effective management. Also, an easier and earlier sampling method than tissue sampling needs to be identified. Serologic testing is an easy and non-invasive method, and samples can be obtained repeatedly along with the treatment phase.

The matrix metalloproteinase (MMP) family consists of 23 zinc-dependent endopeptidases, which are all involved in the degradation of the extracellular matrix. Based on their unique ability to degrade the major constituent of the basement membrane, the gelatinases MMP-2 and MMP-9 are the most important MMPs involved in tumor invasion and metastasis $(3,4)$. MMP-2 and MMP-9 are able to degrade type IV collagen. Type IV collagen is abundant in basement membranes that separate epithelial cells from the underlying stroma. An essential process in initiation of metastasis is the degradation of the extracellular matrix (ECM), which allows the tumor to invade local tissue, intravasate and extravasate the blood vessels and create new metastatic formations. This process is primarily influenced by the activity of proteinases secreted by the tumor (5-8).

MMPs are upregulated in almost every type of cancer and their expression is often associated with a poor prognosis for patients $(9,10)$. Since tissue MMPs may leach into the blood stream and increase the circulating levels, it is believed that MMP profile in the blood could serve as a biological marker for disease onset, progression or monitoring. Previous studies have shown the expression and activity of MMPs to be linked to an advanced stage of breast cancer, increased invasion of tumor cells and building of metastatic formations (11).

However, most reports have focused on tissue MMPs from the primary site of breast cancer. Reports on tissue MMPs from metastatic sites, particularly lymph nodes, are few. In order to evaluate the clinical value of serum MMPs as a 
metastatic biomarker, an association between tissue MMPs from metastatic sites and serum MMP expression should be identified.

In the present study, we investigated the correlation between serum and lymph node MMP expression and axillary node metastasis.

\section{Materials and methods}

Sample collection. A total of 77 patients with invasive ductal carcinoma without clinically apparent distant metastases and 10 patients with benign breast tumor, newly diagnosed at our institutions between 2011 and 2012, were included in the present study. The study design was approved by the institutional review board of the Catholic University of Korea, College of Medicine (IRB approval no. OC11TISI0069) and informed consent was obtained from all patients.

Blood samples were collected from all patients preoperatively following a standardized protocol. Serum samples were prepared by collecting blood in empty tubes which were left at room temperature until centrifugation. Samples were centrifuged for $10 \mathrm{~min}$ at $4,000 \mathrm{rpm}$, then supernatant was transferred to new tubes and immediately stored at $-80^{\circ} \mathrm{C}$ until enzyme-linked immunosorbent assay (ELISA) and gelatin zymography. To ensure the reliability of the measurements, MMP-2 and MMP-9 concentrations were determined in parallel using the ELISA test and gelatin zymography.

We collected axillary lymph node tissue from 77 patients with breast cancer during operation. An average of 5 lymph nodes were selected from each patient. The lymph node was bisected along its longest axis, half of which was stored at $-80^{\circ} \mathrm{C}$ and the remaining half of which was embedded in paraffin and processed for routine histology. Depending on the histologic confirmation, a total of 56 metastatic lymph nodes and 56 non-metastatic lymph nodes were selectively chosen for gelatin zymography. Frozen nodes were ground by a tissue micro-dismembrator (B. Braun Melsungen AG, Melsungen, Germany), resuspended in Tris-HEPES, pH 7.5 buffer, homogenated on ice, centrifuged at $2,000 \mathrm{rpm}$ at $4^{\circ} \mathrm{C}$ for $5 \mathrm{~min}$. The supernatant was collected and used for gelatin zymography evaluation. The samples only underwent one freeze/thaw cycle before measurements were conducted.

ELISA. We quantified the concentrations of both gelatinases in the serum samples processed for zymography. Pro-MMP-2 and pro-MMP-9 were determined by ELISA kits ( $R \& D$ Systems, Minneapolis, MN, USA) based on a double sandwich system whereby the antigen is captured by a primary antibody coated on the well and after extensive washes a secondary antibody conjugated with horseradish peroxidase is added to immobilize the immunocomplex. In both cases, positivity was revealed by tetramethylbenzidine and optical density was read at $450 \mathrm{~nm}$ in a microtiter plate spectrophotometer.

Gelatin zymography. Gelatin zymography was performed as follows: gels (SDS-PAGE, 10\%) were co-polymerized with gelatin $(1 \mathrm{mg} / \mathrm{ml})($ G9382, Sigma Chemical Co., St. Louis, MO, USA). Ten microliters of gel-loading buffer and same amount of sample were loaded onto the wells of the gel. We used HT1080 cell line (Korean Cell Line Bank, Seoul, Korea) conditioned medium as standard control. This conditioned medium is a well known standard for detecting MMP-2 and MMP-9 activity (12). The values of MMP activity were reported as a percentage of active form of total form. To activate latent MMPs (pro-MMP), all samples were incubated with $1 \mathrm{mmol} / \mathrm{l}$ APMA (Sigma) for $3 \mathrm{~h}$ at $37^{\circ} \mathrm{C}$ before loading to gel. Electrophoresis was carried out using the minigel slab apparatus (Mini-PROTEAN; Bio-Rad Laboratories, Hercules, CA, USA) at a constant voltage of $125 \mathrm{~V}$, until the dye reached the bottom of the gel. After electrophoresis, gels were washed in renaturing buffer [2.5\% Triton X-100 in $50 \mathrm{mM}$ Tris- $\mathrm{HCl}$ $(\mathrm{pH} \mathrm{7.5)]} \mathrm{for} 1 \mathrm{~h}$ at room temperature with gentle agitation. Then, the zymograms were incubated for $18 \mathrm{~h}$ at $37^{\circ} \mathrm{C}$ in developing buffer $\left[5 \mathrm{mM} \mathrm{CaCl}_{2}, 3 \mathrm{mM} \mathrm{NaN}_{3}\right.$ in $50 \mathrm{mM}$ Tris- $\mathrm{HCl}$ (pH 7.5)]. Gels were then stained with Coomassie blue and destained with $30 \%$ methanol and $10 \%$ acetic acid. Gels were acquired and photographed by gel imaging system (Molecular Imager ${ }^{\circledR}$ Gel DocTM XR; Bio-Rad Laboratories), and the area of destained band was then measured in pixels for band intensity with an image analysis software system (ImageJ 1.45s; National Institutes of Health, Bethesda, MD, USA) for quantification. These data were normalized to the value of a standard band (HT1080) and were represented as the fold-change over control values.

Statistical analysis. All statistical analyses were performed by SPSS for Windows v. 19.0 (SPSS Inc., Chicago, IL, USA). ELISA data were found not to be normally distributed and were therefore analyzed by the non-parametric Mann-Whitney U test. Gelatin zymography data were found to be normally distributed and were analyzed with the unpaired Student's t-test. Pearson's correlation coefficient analysis was calculated to determine the association between the serum and tissue levels of MMP-2 and MMP-9. In all cases, differences were considered statistically significant for values of $\mathrm{P}<0.05$.

\section{Results}

Patient characteristics. The patient population consisted of 77 patients with primary breast cancer aged between 27-79 years (52.03 \pm 9.5 years) and 10 patients with benign breast tumor aged between $20-53$ years ( $35.1 \pm 13.72$ years). All breast cancer types were invasive ductal carcinoma and the pathology of the benign tumor group was only fibroadenoma. The clinicopathological characteristics of the breast cancer patients area listed in Table I.

Serum levels and activities of MMP-2 and MMP-9. The gelatin zymography assay was optimized to quantify MMP-2 and MMP-9 in both latent and active form in serum sample preparations (Fig. 1). A statistically significant difference in MMP-2 and MMP-9 levels was noted between the breast cancer and benign breast tumor patient group [MMP-2, mean 2.76 vs. 1.57 (x fold-change), $\mathrm{P}<0.001$; MMP-9, mean 7.26 vs. 2.45 (x foldchange), $\mathrm{P}<0.001]$. The activity of MMPs was measured as the ratio (\%) of active form to total form; active and total form of MMPs were quantified by the area of destained band on the gel. No such differences were found in MMP-2 and MMP-9 activity between the two groups. 
Table I. Characteristics of breast cancer patients $(\mathrm{N}=77)$.

\begin{tabular}{|c|c|c|}
\hline & $\mathrm{N}$ & $\%$ \\
\hline \multicolumn{3}{|l|}{ Age (years) } \\
\hline Mean \pm SD & $52.03 \pm 9.50$ & \\
\hline \multicolumn{3}{|l|}{ T stage } \\
\hline $\mathrm{T} 1$ & 31 & 40.2 \\
\hline $\mathrm{T} 2$ & 41 & 53.2 \\
\hline T3 & 5 & 6.4 \\
\hline \multicolumn{3}{|l|}{ N stage } \\
\hline N0 & 42 & 54.5 \\
\hline N1 & 24 & 31.1 \\
\hline $\mathrm{N} 2$ & 5 & 6.4 \\
\hline N3 & 6 & 7.7 \\
\hline \multicolumn{3}{|l|}{ Stage } \\
\hline I & 23 & 29.8 \\
\hline IIA & 27 & 35.0 \\
\hline IIB & 15 & 19.4 \\
\hline III & 12 & 15.5 \\
\hline \multicolumn{3}{|c|}{ Histologic grade } \\
\hline G1 & 34 & 44.1 \\
\hline $\mathrm{G} 2$ & 34 & 44.1 \\
\hline G3 & 9 & 11.6 \\
\hline \multicolumn{3}{|l|}{ Nuclear grade } \\
\hline N1 & 5 & 6.4 \\
\hline $\mathrm{N} 2$ & 39 & 50.6 \\
\hline N3 & 33 & 42.8 \\
\hline \multicolumn{3}{|c|}{ Estrogen receptor } \\
\hline Negative & 32 & 41.5 \\
\hline Positive & 45 & 58.4 \\
\hline \multicolumn{3}{|c|}{ Progesterone receptor } \\
\hline Negative & 41 & 53.2 \\
\hline Positive & 36 & 46.7 \\
\hline \multicolumn{3}{|l|}{ HER-2 } \\
\hline Negative & 55 & 71.4 \\
\hline Positive & 22 & 59.4 \\
\hline
\end{tabular}

In terms of node positivity, serum MMP-2 levels were significantly higher in node-positive patients compared to node-negative patients [mean 3.47 vs. 2.23 (x fold-change); $\mathrm{P}<0.001]$, and higher serum MMP-9 levels were found in node-positive patients compared to node negative patients, significantly [mean 8.44 vs. 6.17 (x fold-change); $\mathrm{P}=0.047$ ). No such differences were found in the activity of MMP-2 and MMP-9 between the two groups (Table II).

To ensure the reliability of the measurements, MMP-2 and MMP-9 concentrations were determined in parallel using the ELISA test and gelatin zymography. MMP-2 (16.35 \pm 3.03 vs. $14.73 \pm 2.82 \mathrm{ng} / \mathrm{ml} ; \mathrm{P}=0.050)$ and MMP-9 levels $(1.59 \pm 1.44$ vs. $0.73 \pm 0.39 \mathrm{ng} / \mathrm{ml} ; \mathrm{P}=0.033$ ) determined by ELISA were significantly more concentrated in breast cancer patients than in benign breast tumor patients. In terms of node positivity, MMP-2 (17.76 \pm 2.82 vs. $15.14 \pm 2.71 \mathrm{ng} / \mathrm{ml} ; \mathrm{P}=0.004)$

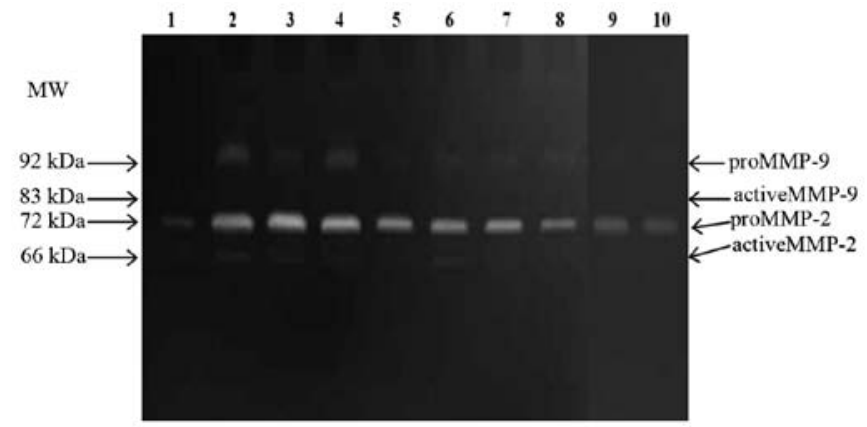

Figure 1. Gelatin zymogram of serum samples. A medium from HT1080 was used as standard control (lane 1); serum of node-positive patients (lanes 2-4); serum of node-negative patients (lanes 5-8); serum of benign breast tumor patients (lanes 9 and 10); MMP-9 and MMP-2 were more noticeable in cancer than in benign patients, and in node-positive than in node-negative patients. Both MMP-9 and MMP-2 activities were expressed too weakly to distinguish the difference.
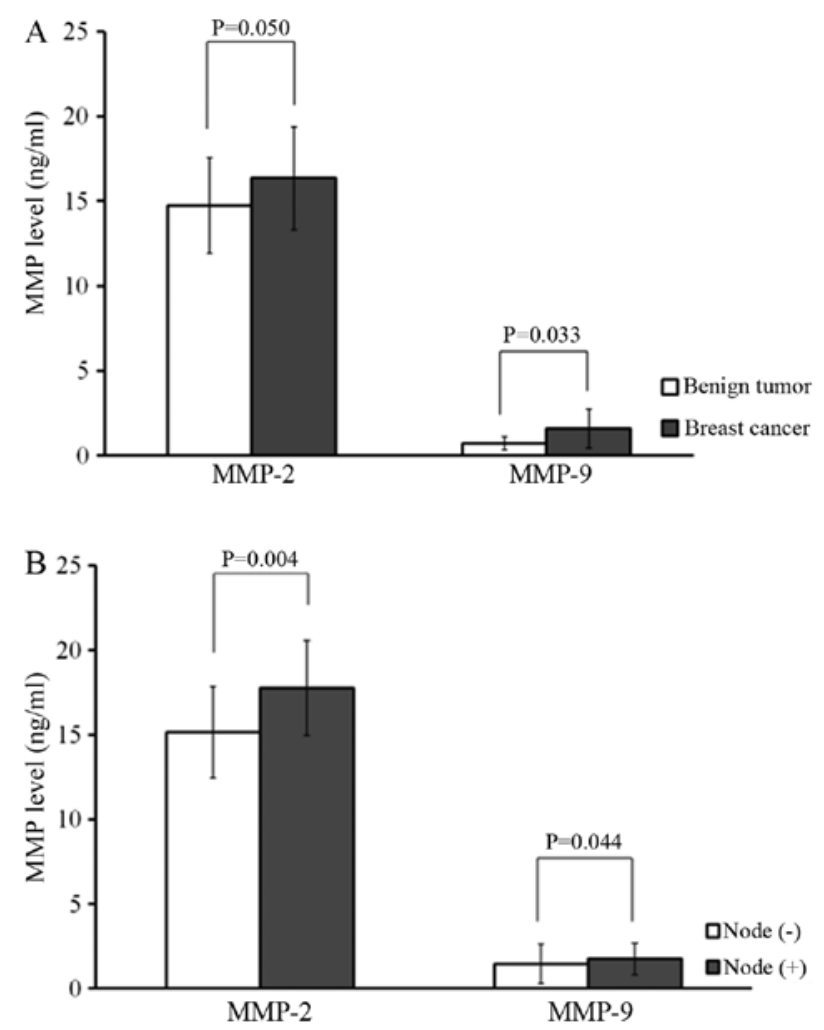

Figure 2. ELISA results of MMP-2 and MMP-9 in benign tumor, breast cancer (A), node positive and node negative (B) groups. MMP-2 and MMP-9 levels in the breast cancer group were more concentrated than in the benign tumor groups and in the node positive than in the node negative groups.

and MMP-9 (1.75 \pm 0.93 vs. $1.46 \pm 1.77 \mathrm{ng} / \mathrm{ml} ; \mathrm{P}=0.044)$ levels were significantly higher in node-positive patients than in node-negative patients (Fig. 2). Pearson correlation coefficient analyses revealed a correlation between ELISA and gelatin zymography results for both MMP-2 and MMP-9 in each sample $(\mathrm{r}=0.76, \mathrm{P}=0.001$ and $\mathrm{r}=0.81, \mathrm{P}=0.001)$ as shown in Fig. 3.

Tissue levels of MMP-2 and MMP-9 in the lymph node. Quantitative analysis of the tissue samples from lymph nodes 
Table II. Serum zymogram results of MMP-2 and MMP-9 in benign tumor, breast cancer, node positive and node negative groups.

\begin{tabular}{lccccrr}
\hline & $\begin{array}{c}\text { Benign tumor } \\
(\mathrm{n}=10)\end{array}$ & $\begin{array}{c}\text { Breast cancer } \\
(\mathrm{n}=77)\end{array}$ & P-value $^{\mathrm{a}}$ & $\begin{array}{c}\text { Node }(+) \\
(\mathrm{n}=35)\end{array}$ & $\begin{array}{c}\text { Node (-) } \\
(\mathrm{n}=42)\end{array}$ & P-value $^{\mathrm{b}}$ \\
\hline MMP-2 (x fold-change) & 1.57 & 2.76 & $<0.001$ & 3.47 & 2.23 & $<0.001$ \\
MMP-2 activity (\%) & 8.2 & 12.5 & 0.480 & 13.1 & 12.0 & 0.808 \\
MMP-9 (x fold-change) & 2.45 & 7.26 & $<0.001$ & 8.44 & 6.17 & 0.047 \\
MMP-9 activity (\%) & 81.6 & 85.8 & 0.222 & 84.0 & 78.4 & 0.128 \\
\hline
\end{tabular}

MMP data are mean values represented as the fold-change over control values. The values of MMP activity are presented as a percentage of active form of total form; ${ }^{a}$ Mann-Whitney $U$ test; ${ }^{b}$ unpaired Student's t-test.

Table III. Tissue zymogram results of MMP-2 and MMP-9 in metastatic node and non-metastatic node groups.

\begin{tabular}{lccc}
\hline & Metastatic node $(\mathrm{n}=56)$ & Non-metastatic node $(\mathrm{n}=56)$ & P-value $^{\mathrm{a}}$ \\
\hline MMP-2 (x fold-change) & 3.79 & 0.95 & 0.05 \\
MMP-2 activity (\%) & 67.5 & 74.8 & 0.676 \\
MMP-9 (x fold-change) & 30.42 & 7.98 & 0.048 \\
MMP-9 activity (\%) & 58.6 & 42.7 & 0.001 \\
\hline
\end{tabular}

MMP data are mean values represented as the fold-change over control values. The values of MMP activity are presented as a percentage of active form of total form. ${ }^{\text {a } u n p a i r e d ~ S t u d e n t ' s ~ t-t e s t . ~}$
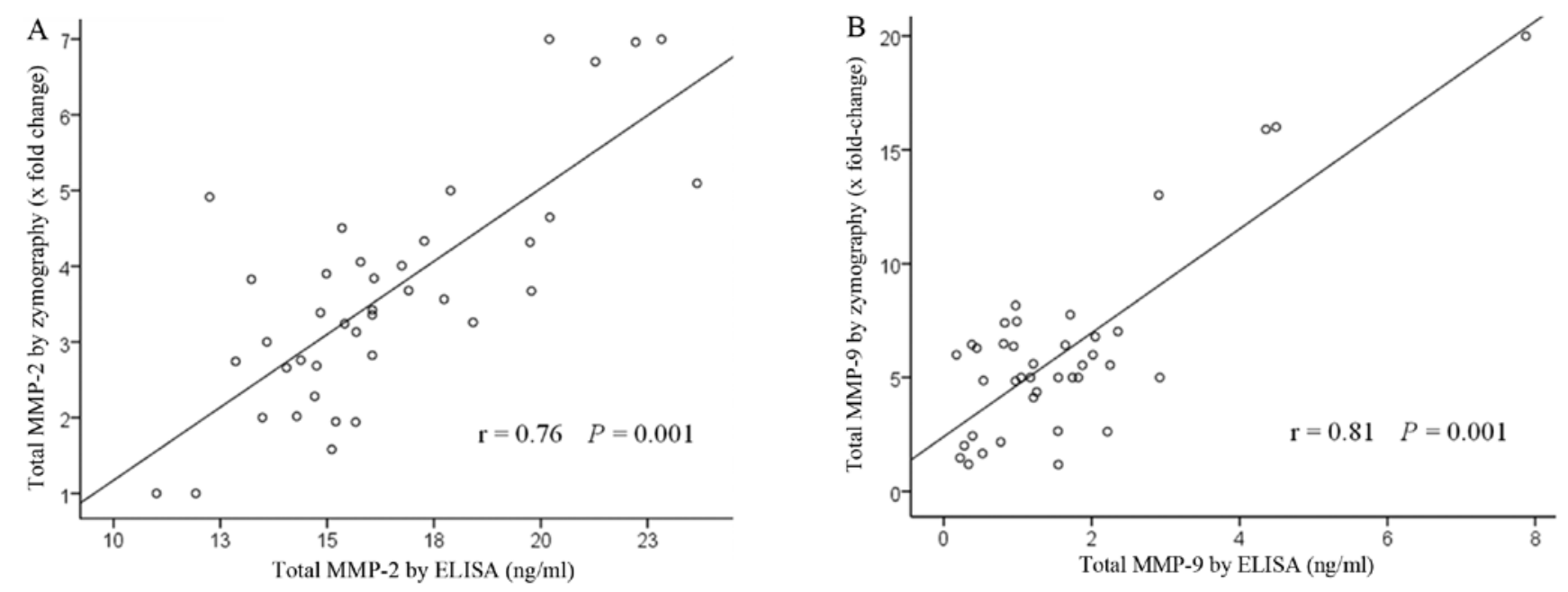

Figure 3. Correlation between total MMP-2 (A) and total MMP-9 (B) levels in the serum by ELISA and gelatin zymography. Pearson correlation coefficient analyses revealed a strong correlation between ELISA and gelatin zymography results for both total MMP- 2 and total MMP-9 in the serum ( $\mathrm{r}=0.76$, $\mathrm{P}=0.001$ and $\mathrm{r}=0.81, \mathrm{P}=0.001)$.

was carried out by gelatin zymography (Fig. 4). The total forms of MMP-2 and MMP-9 in the lymph nodes were significantly higher in the metastatic than in the non-metastatic node group [MMP-2, mean 3.79 vs. 0.95 (x fold-change), $\mathrm{P}=0.050$; MMP-9, mean 30.42 vs. 7.98 (x fold-change), $\mathrm{P}=0.048]$. In the metastatic node group, a proportion of the active MMP-9 was significantly higher than in the non-metastatic node group (mean 58.6 vs. $42.7 \%$; $\mathrm{P}=0.001$ ), whereas MMP-2 activities did not show a significant difference (Table III).
Correlation of zymographic results of MMP-2 and MMP-9 levels between the serum and lymph node. Fig. 5 shows the correlation of MMP-2 and MMP-9 levels between the serum and lymph node. The patients with elevated serum levels had high lymph node levels. A positive correlation was found between serum total MMP-9 levels and lymph node levels, significantly $(\mathrm{r}=0.34, \mathrm{P}=0.011)$. By contrast, no statistical difference was observed with total MMP-2 levels ( $r=-0.045$, $\mathrm{P}=0.752$ ). 


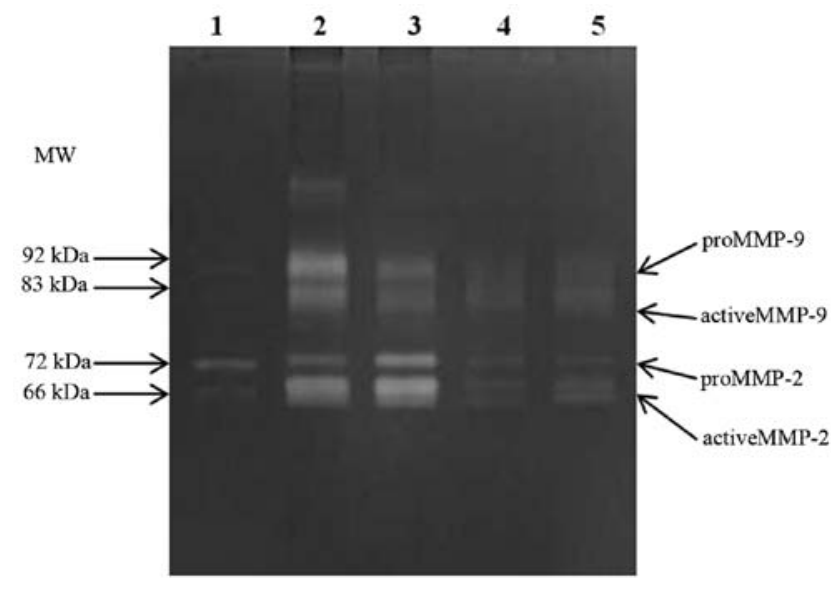

Figure 4. Gelatin zymogram of lymph node tissue samples. A medium from HT1080 was used as standard control (lane 1); tissue of metastatic lymph node (lanes 2 and 3); tissue of non-metastatic lymph node (lanes 4 and 5); MMP-9, MMP-2 and MMP-9 activity were detected more prominently in metastatic lymph node than in non-metastatic lymph node.
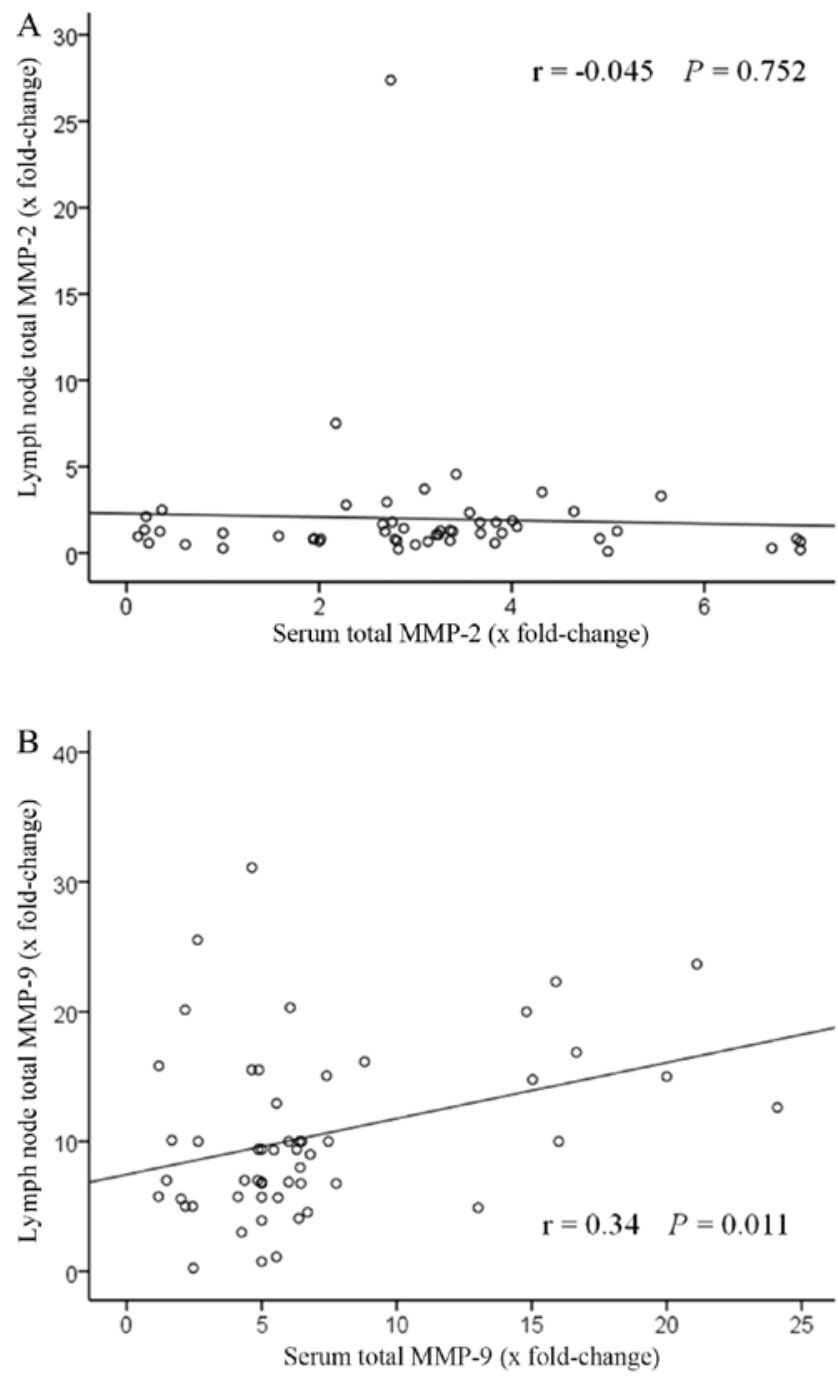

Figure 5. Correlation of total MMP-2 (A) and MMP-9 (B) levels between the serum and lymph node. A significant positive correlation was found between serum total MMP-9 levels and lymph node levels $(r=0.34, \mathrm{P}=0.011)$. By contrast, a non-significant negative correlation was found with total MMP-2 $(r=-0.045, P=0.752)$.

\section{Discussion}

MMPs have been reported to be involved in metastasis in several types of cancer including breast cancer (13-19). Several authors have reported clinical correlations between MMP levels in the serum and in the tissue from primary lesions of breast cancer. However, these studies did not include metastatic lesions, particularly the lymph node. Limited studies have assessed the tissue level of MMPs in the lymph node (20).

The aim of the present study was to investigate the clinical value of MMP-2 and MMP-9 levels in the sera and axillary lymph node of breast cancer patients. In the sera, the results of the present study showed a statistically significant difference in MMP-2 and MMP-9 levels between the breast cancer and benign breast tumor patient group. Furthermore, higher levels of both gelatinases were noted in the serum of node-positive patients than node-negative patients among breast cancer patients. These results are similar to those found in the current literature $(21,22)$. In the axillary lymph node tissue, the results of the present study showed higher levels of total MMP-9, total MMP-2 and MMP-9 activities in metastatic lymph nodes than in non-metastatic lymph nodes.

We assessed the correlation between high serum levels of both gelatinases with high tissue levels from a single patient. Serum levels of both gelatinases seem to be indicators of axillary lymph node metastasis and high malignant potential if they are positively correlated with high levels measured in the lymph node. The present study suggests that higher levels of total MMP-9 measured in the serum and lymph node are associated with node metastasis, and that measurements of the two clinical parameters from a single patient have a positive correlation. These data are important from two perspectives; firstly, this biological marker could be used to diagnose axillary lymph node metastasis preoperatively in addition to established imaging test and, thus, minimize the extent of surgical removal in axilla to lower surgical complication rate. Secondly, it could be useful to predict disease progression, survival and metastasis.

Notably, MMP-9 activity and MMP-2 activity in the serum and tissue showed no significant deferences between the metastatic and non-metastatic node group. We assume the reason is that it is difficult to quantify active form and determine actual activity of MMPs. In the first place, gelatin zymography does not identify activity of MMPs inhibited by tissue inhibitors of metalloproteinases (TIMPs) or $\alpha_{2}$-macroglobulin. Secondly, the zymographical method contains the SDS in the sample buffer that could have an effect on the activity of the MMPs and the dissolution of complexes of MMPs with TIMPs. In addition, serum sample contains neutrophils and macrophages that produce and secrete various MMPs (23), that might complicate the analysis of activity of MMPs.

Nevertheless, from the results of the present study that MMP-9 in breast cancer patient's serum correlates with that in their axillary lymph node, MMP-9 may be a useful biomarker. It has been reported that high levels of plasma activity of MMP-9 could be adequate in describing the aggressive biological behavior of breast tumors as it was useful as a prognostic factor (24).

We analyzed the correlation of serum MMP levels with clinical parameters to relate our data with disease features. 
Univariate analysis revealed no correlation between both gelatinases and established prognostic factors for breast cancer, such as tumor size, histologic grade, nuclear grade, tumor staging, c-erbB-2 expression, estrogen receptor concentration and progesterone receptor concentration (data not shown). They may result from the limited number of samples and patients in the present study and further studies are required to validate the association between our results and clinical parameters.

In conclusion, the present study demonstrated a correlation between serum and lymph node MMP-9 levels in breast cancer patients, which suggests a potential to use MMP-9 as a predictor of breast cancer development, progression and axillary node metastasis.

\section{Acknowledgements}

The present research was supported by the Korea Breast Cancer Foundation.

\section{References}

1. Goldhirsch A, Glick JH, Gelber RD, Coates AS, Thurlimann B and Senn HJ: Meeting highlights: international expert consensus on the primary therapy of early breast cancer 2005. Ann Oncol 16: 1569-1583, 2005.

2. Thomssen C and Janicke F: Do we need better prognostic factors in node-negative breast cancer? Eur J Cancer 36: 293-298, 2000.

3. Talvensaari-Mattila A,Paakko P,Hoyhtya M,Blanco-Sequeiros G and Turpeenniemi-Hujanen T: Matrix metalloproteinase-2 immunoreactive protein: a marker of aggressiveness in breast carcinoma. Cancer 83: 1153-1162, 1998.

4. Li HC, Cao DC, Liu Y, et al: Prognostic value of matrix metalloproteinases (MMP-2 and MMP-9) in patients with lymph node-negative breast carcinoma. Breast Cancer Res Treat 88 : $75-85,2004$

5. Giambernardi TA, Grant GM, Taylor GP, et al: Overview of matrix metalloproteinase expression in cultured human cells Matrix Biol 16: 483-496, 1998.

6. Iwasaki M, Nishikawa A, Fujimoto T, et al: Anti-invasive effect of MMI-166, a new selective matrix metalloproteinase inhibitor, in cervical carcinoma cell lines. Gynecol Oncol 85: 103-107, 2002.

7. Kato Y, Yamashita $\mathrm{T}$ and Ishikawa M: Relationship between expression of matrix metalloproteinase-2 and matrix metalloproteinase- 9 and invasion ability of cervical cancer cells. Oncol Rep 9: 565-569, 2002.

8. McMasters KM, Giuliano AE, Ross MI, et al: Sentinel-lymphnode biopsy for breast cancer - not yet the standard of care. N Engl J Med 339: 990-995, 1998.
9. Curran S, Dundas SR, Buxton J, Leeman MF, Ramsay R and Murray GI: Matrix metalloproteinase/tissue inhibitors of matrix metalloproteinase phenotype identifies poor prognosis colorectal cancers. Clin Cancer Res 10: 8229-8234, 2004

10. Forget MA, Desrosiers RR and Beliveau R: Physiological roles of matrix metalloproteinases: implications for tumor growth and metastasis. Can J Physiol Pharmacol 77: 465-480, 1999.

11. Duffy MJ, Maguire TM, Hill A, McDermott E and O'Higgins N: Metalloproteinases: role in breast carcinogenesis, invasion and metastasis. Breast Cancer Res 2: 252-257, 2000.

12. Giannelli G, Bergamini C, Fransvea E, Marinosci F, Quaranta V and Antonaci S: Human hepatocellular carcinoma (HCC) cells require both alpha3beta1 integrin and matrix metalloproteinases activity for migration and invasion. Lab Invest 81: 613-627, 2001.

13. Vasala K, Paakko P and Turpeenniemi-Hujanen T: Matrix metalloproteinase-2 immunoreactive protein as a prognostic marker in bladder cancer. Urology 62: 952-957, 2003.

14. Gerhards S, Jung K, Koenig F, et al: Excretion of matrix metalloproteinases 2 and 9 in urine is associated with a high stage and grade of bladder carcinoma. Urology 57: 675-679, 2001.

15. Liabakk NB, Talbot I, Smith RA, Wilkinson K and Balkwill F: Matrix metalloprotease 2 (MMP-2) and matrix metalloprotease 9 (MMP-9) type IV collagenases in colorectal cancer. Cancer Res 56: 190-196, 1996.

16. Liotta LA, Tryggvason K, Garbisa S, Hart I, Foltz CM and Shafie S: Metastatic potential correlates with enzymatic degradation of basement membrane collagen. Nature 284: 67-68, 1980.

17. Davies B, Miles DW, Happerfield LC, et al: Activity of type IV collagenases in benign and malignant breast disease. Br J Cancer 67: 1126-1131, 1993

18. Brown PD, Bloxidge RE, Anderson E and Howell A: Expression of activated gelatinase in human invasive breast carcinoma. Clin Exp Metastasis 11: 183-189, 1993.

19. Di Carlo A, Terracciano D, Mariano A and Macchia V: Matrix metalloproteinase-2 and matrix metalloproteinase-9 type IV collagenases in serum of patients with pleural effusions. Int $\mathrm{J}$ Oncol 26: 1363-1368, 2005 .

20. Daniele A, Zito AF, Giannelli G, et al: Expression of metalloproteinases MMP-2 and MMP-9 in sentinel lymph node and serum of patients with metastatic and non-metastatic breast cancer. Anticancer Res 30: 3521-3527, 2010.

21. Hanemaaijer R, Verheijen JH, Maguire TM, et al: Increased gelatinase-A and gelatinase-B activities in malignant vs. benign breast tumors. Int J Cancer 86: 204-207, 2000.

22. Zucker S, Hymowitz M, Conner C, et al: Measurement of matrix metalloproteinases and tissue inhibitors of metalloproteinases in blood and tissues. Clinical and experimental applications. Ann NY Acad Sci 878: 212-227, 1999.

23. Kjeldsen L, Bjerrum OW, Hovgaard D, Johnsen AH, Sehested M and Borregaard N: Human neutrophil gelatinase: a marker for circulating blood neutrophils. Purification and quantitation by enzyme linked immunosorbent assay. Eur J Haematol 49: 180-191, 1992.

24. Ranuncolo SM, Armanasco E, Cresta C, Bal De Kier Joffe E and Puricelli L: Plasma MMP-9 (92 kDa-MMP) activity is useful in the follow-up and in the assessment of prognosis in breast cancer patients. Int J Cancer 106: 745-751, 2003. 